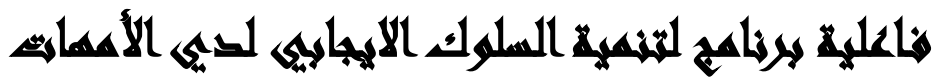

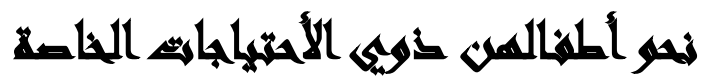

\section{$[1 \cdot]$}

جمال أحمد شفيق(')- مني حسين الدهان(广)- أحمد فخري هاني()- رحاب شريف حسن

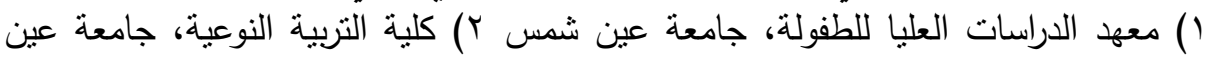

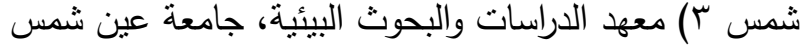

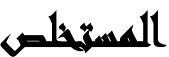

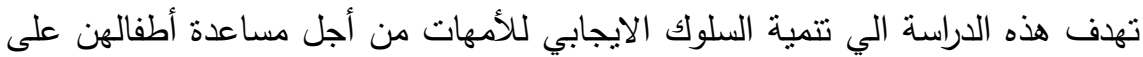

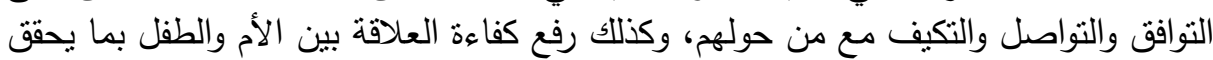

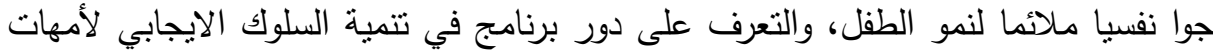

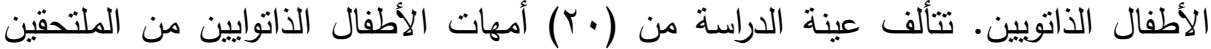

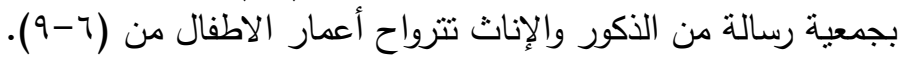

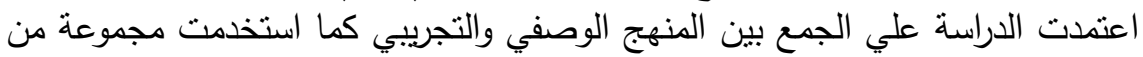

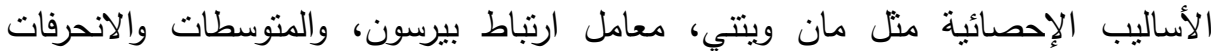
المعيارية، كما اعتمدت الدراسة علي مقياس الرئية الرعاية الوالدية من اعداد الباد الباحث.

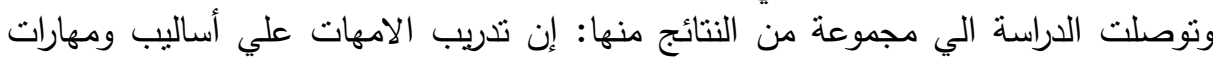

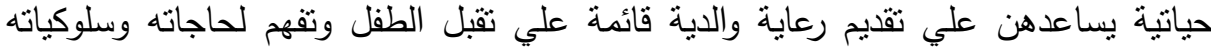
المضطربة؛ إقامة علاقة وطيدة بين الأب والأم والطفل الذانوي بنائة يساعد في التخفيض من أعراض الذاتوية لديه. كما انتهت الي مجموعة من التوصيات: منها ضرورة الاهنمام بتقديم المزيد من البرامج

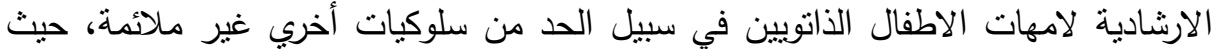
تعد الام هي الاكثر تعاملاً مع الطفل والأكثر احتكاكاً به والاكثر تلبية لاحتياجيات الانه.

\section{ranadl}

تعد الذاتوية من الفئات الخاصة التي تحتاج إلى رعاية وتدريب وتعليم وتأهيل يؤدي إلى زيادة كفاءة من يعانون منها، وتتمية قدراتهم ومهاراتهم وتقويم سلوكهم من أجل التمهيد لعودتهم

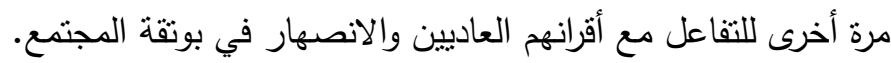

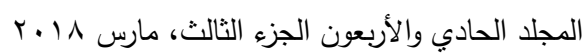


إضافة إلى ذلك نجد تأثثر الطفل الذاتوي على أسرته تأثيرا بالغا وربما لا توجد ظروف

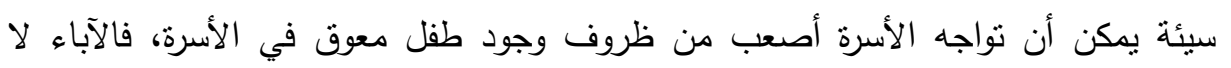

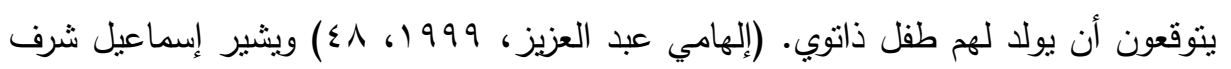

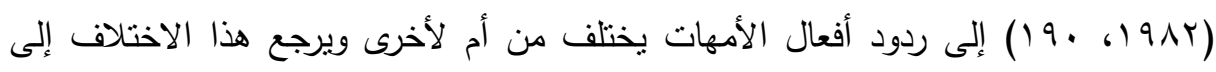

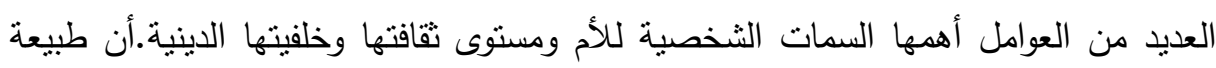
العلاقة الزوجية تعد من العوامل الهامة في نوافق الأم مع إعاقة طفلها. إن الأم تعد هي الأني

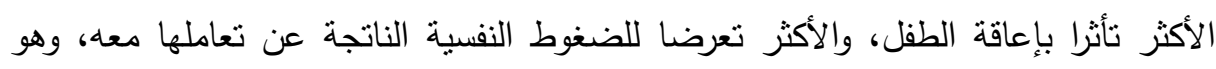
الأمر الذي يحتم ضرورة إرشادها حيث إن عدم وعيها بطبيعة الاضطرابات أو بالأساليب

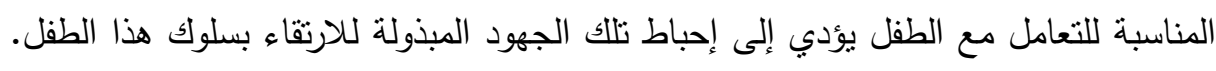

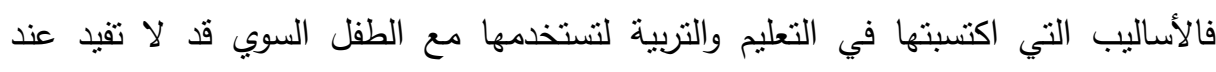
استخدامها مع الأطفال الذاتويين بل ربما تؤدي إلى نتائج عكسية تضعها في حيرة شديدة. وقد

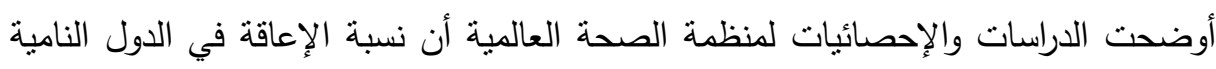
والدول المتعرضة للحروب ما بين (• (-r إ\%) من عدد السكان في تلك الدول.

\section{ميف2 التواسمة}

إن تتمية السلوك الايجابي لأمهات الأطفال الذاتوبين يعد المحور الرئيسي لمشكلة

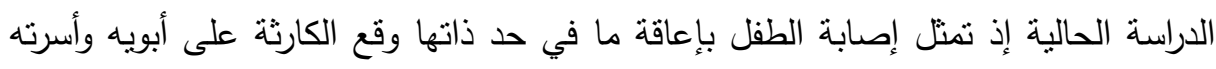
خاصة ومجتمعه عامة. تعد الأم هي الأقرب إلى الطفل والأكثر تعاملا معه واحتكاكا به وهي المسئولة بدرجة

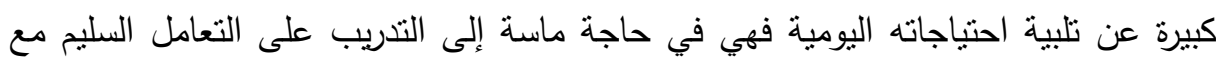
طفلها وتتجيعه على اكتساب السلوك الاجتماعي المرغوب فيه والتخلص من مظاهر السلوك هليه

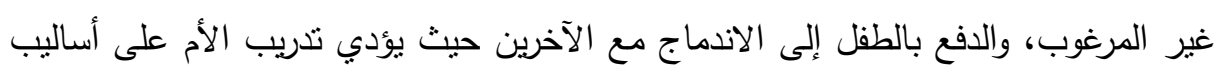

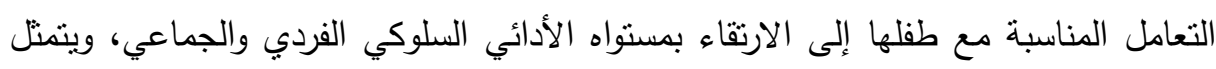

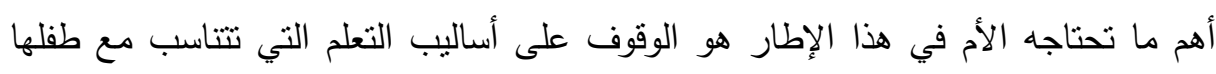

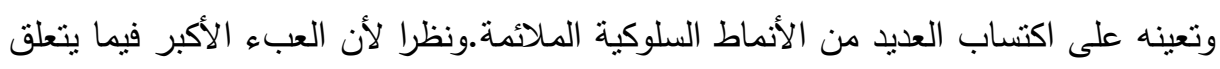

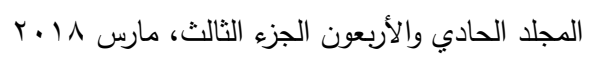


برعاية الطفل ذي الاحتياجات الخاصة وتوجيهه يتم على عاتق الأم حيث هي الأكثر تعاملا

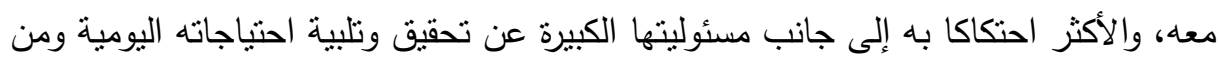

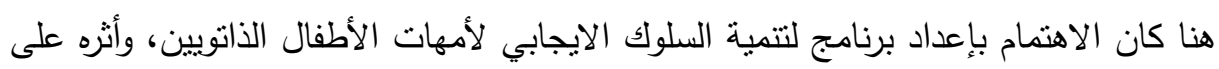

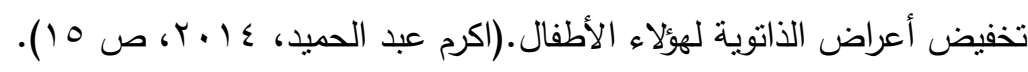

\section{تمساولائد الصواسمد}

ا. ما أهم السلوكيات الايجابية التي يمكن أن تتدرب عليها الأمهات (عينة الدراسة) من خلد

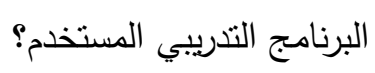

r. الي أي مدي يساعد البرنامج التدريبي في تتمية السلوك الايجابي لدي الامهات؟

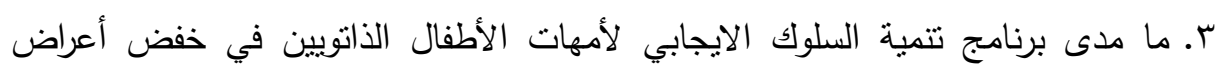
الذاتوية لدى أبنائهن؟ مانج

ع. ما مدى إمكانية استمرار تحسن السلوكيات الايجابية للأكهات على سلوك أبنائهن الذاتوبين والتخفيض من أعراض الذاتوية لديهج?

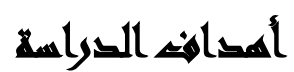

ا ـ تتمبة مهارات الرعاية الوالدية للأمهات من أجل مساعدة أطفالهن على التوافق والتواصل والتكيف مع من حولهم (مهارة رعاية الذات، العلاقات داخل الأسرة، مهارة التواصل).

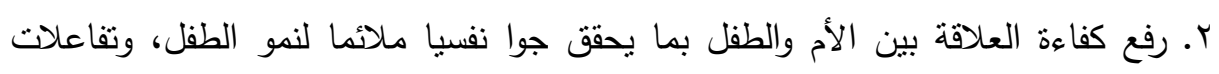
سوية.

r. التعرف على دور برنامج في تتمية السلوك الايجابي لأمهات الأطفال الذاتويين وخفض أعراض الذاتوية لهؤلاء الأطفال.

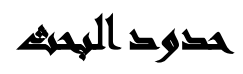

المجال المكاني: مركز رسالة لذوي الاحتياجات الخاصة بمدينة نصر .

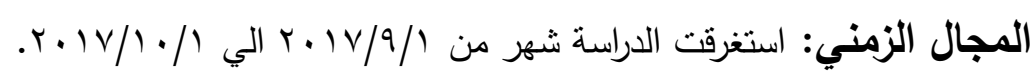

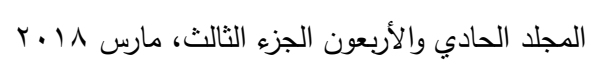


مجلة العلوم البيئية

معهز الدراسات والبحوث البيئية - جامعة عين شمس لهن

\section{هنهمج التواسمة}

تعتمد الدراسة علي المنهج التجريبي فهو ضروري لطبيعة الدراسة الحالية وأهدافها، فالهدف الأساسي للاراسة هو بناء برنامج تدريبي إرشادي سلوكي للرعاية الوالدية لأمهات

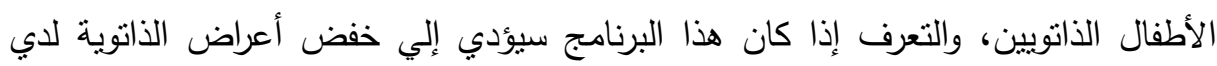
أطفالهن عينة الدراسة.

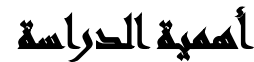

أولاً: الجانب النظري: تتبلور أهمية الدراسة الحالية في الحاجة دراسات تتتاول أساليب الرعاية الوالدية والنتشئة الاجتماعية للأطفال الذاتويين مما يساعد هؤلاء الأطفال في تعديل

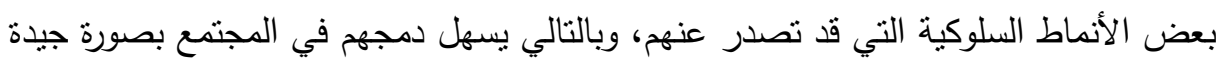
وسيساعد أيضا الأسرة في التعامل مع هؤلاء الأطفال بشكل مناسب وبطريقة علمية وسلية وسليمة. ثانياً: الجانب التطبيقي:

(1) إنها تقدم برنامجا تدريبيا لتتمية بعض السلوك الايجابي لأمهات الأطفال الذاتويين (عينة

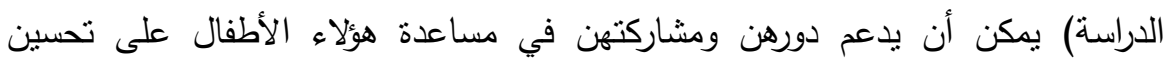

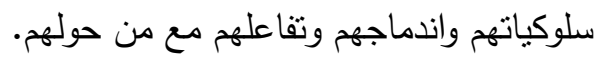
r) إن تقديم الخدمة المنكاملة لهؤلاء الأطفال لا يتم إلا بإرشاد الأسرة وخاصة الأم حيث تضطلع بدور أساسي في توجيه الطفل وتشخيص سلوكه.

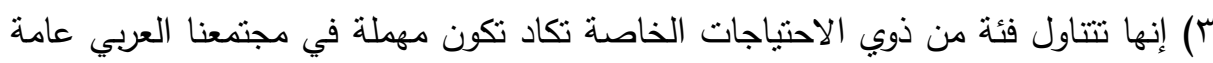
على الرغم من تتاولها باهتمام في البلدان المتقدمة.

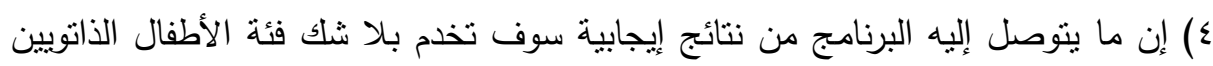
وأسرهم وتخفف من وطأة الضغوط الوالدية. 


\section{همطللجاهي اللهميث}

ا. مفهوم البرنامج: البرنامج هو مجموعة من الأنثطة والممارسات العلمية التي يقوم بها

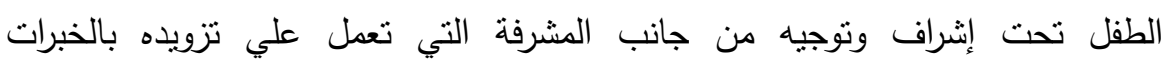

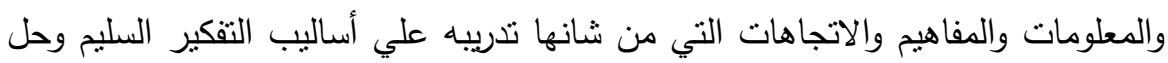

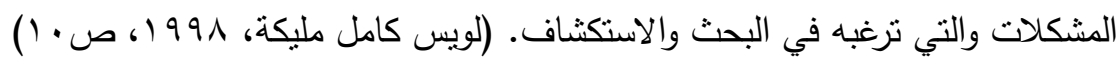
r. مفهوم التتمية: التتمية عملية نفسية وتربوية مستمرة تتغير تبعاً لحاجات الفرد الأساسية وتتم

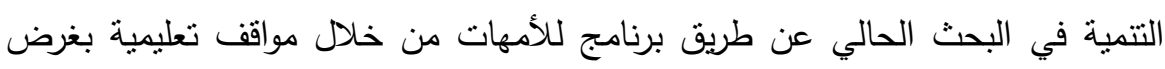
إكسابها بعض الكفاهيم في خطة زمنية محددة لتنمية السلوك الايجابي لديها نحو أبنائها.

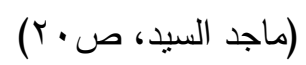

r. تعريف الأطفال ذو الاحتباجات الخاصة: أن الأطفال ذوي الاحتباجات الخاصة هم الذين الأناء

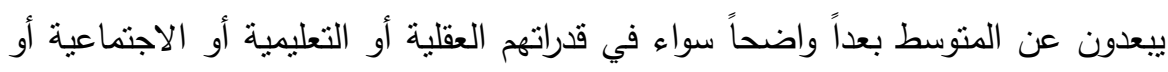

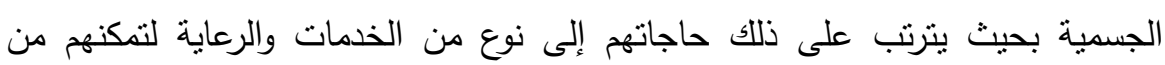
تحقيق أقصى ما تسمح به قدراتهم.

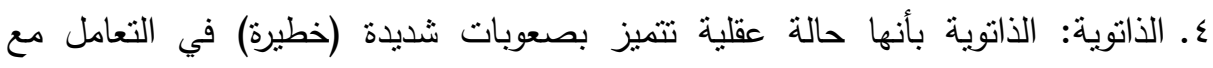
الآخرين واستخدام اللغة واستخدام الدفاهيم الدجردة. (ماجد السيد، مرجع سابق ذكرة

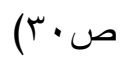

\section{الصواسايت المايوية}

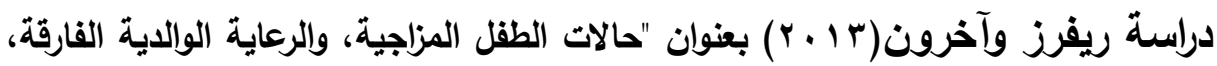

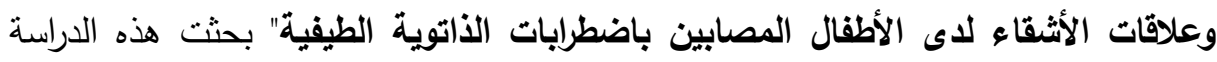

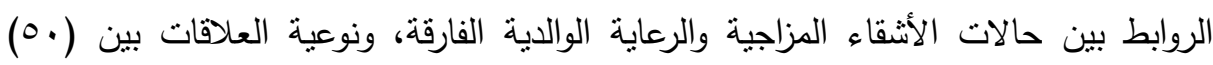

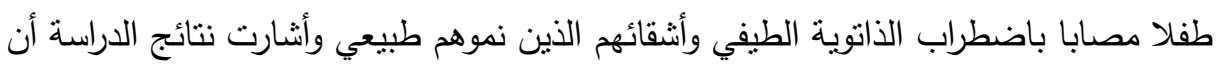

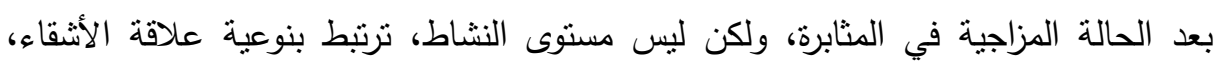

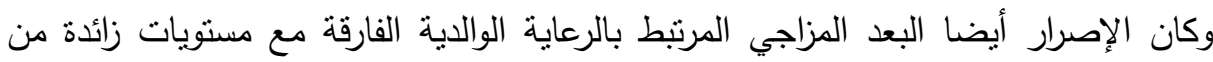

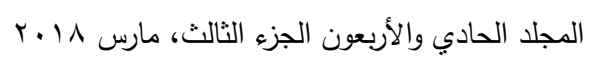


الرعاية الوالدية الفارقة التى تحدث عند ما كان الأثقاء وإلى درجة ما الأطفال المصابين

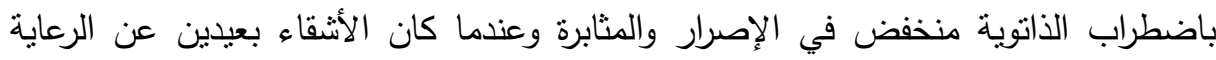
الوالدية الفارقة تم التوصل إلى حل وسط فيما يتعلق بعلاقة الأشقاء.

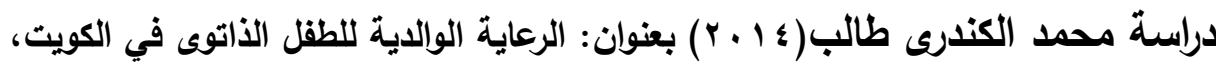
صوت وخبرات الأمهات الكويتيات اللاتي لديهن أطفال ذاتويون، هدفت هذه الدراسة الوصفية

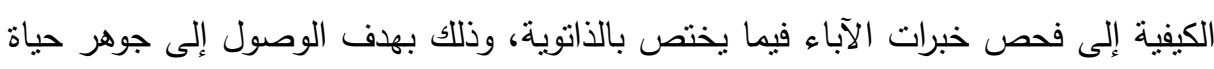

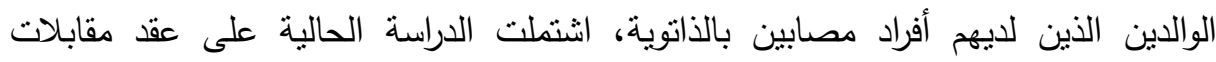

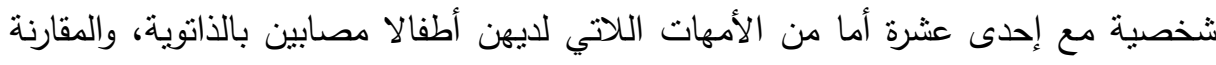

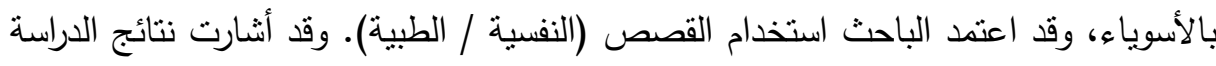

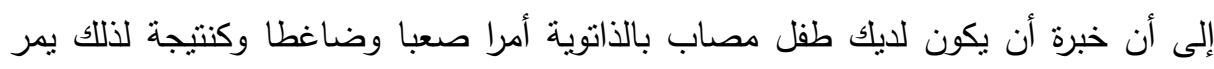
الوالدان بمراحل الإدراك، وبعد ذلك ينظمون مجهوداتهم ومواردهم لمساعدة أطفالهم.

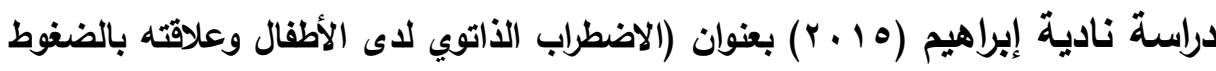

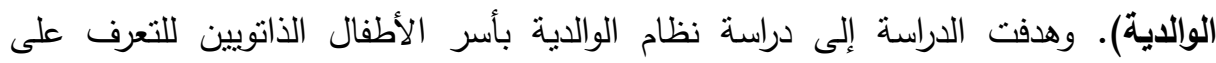

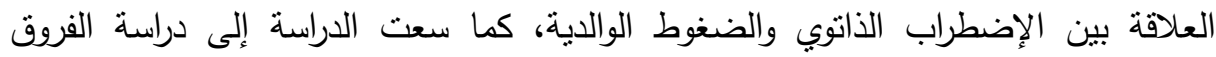

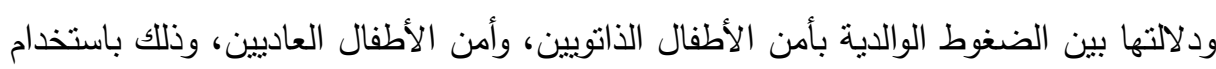

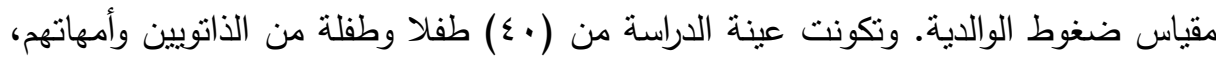

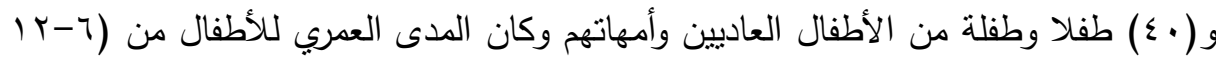
سنة). وأظهرت نتائج الدراسة وجود علاقة ارتباطية إيجابية دالة بين الاضطراب الذاتوي والضغوط الوالدية. وجود علاقة ارتباطية إيجابية دالة بين ثلاثة أبعاد من خصائص الطفل الذانوي درجات تدعيم الطفل للوالدين مع الرابطة العاطفية بالطفل، درجات الحالة المزاجية للطفل مع الرابطة العاطفية بالطفل. 


\section{الاطار اللنظيه}

المحور الأول يعتمد علي نظريات التعلم ويمنلها التعليم الاشتراطي (بافلوف) والاجرائي (سكينر). ووفقا للمحور الاول (السبافلوف وسكينر) فإن أنماط السلوك الاجتماعي يمكن النئن

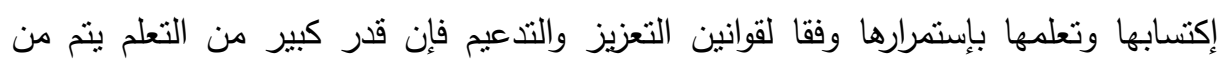

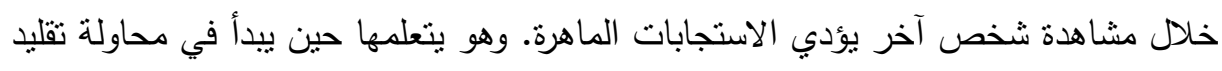

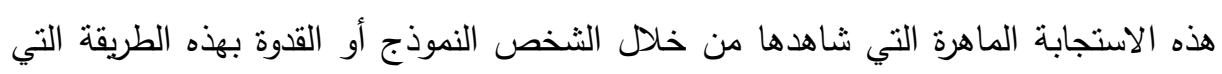
يمكن للمشاهد أن يتعلم.

أما المحور الثاني الذي يعتمد علي نظرية التعلم الاجتماعي فيعتبر باندورا الثخصية

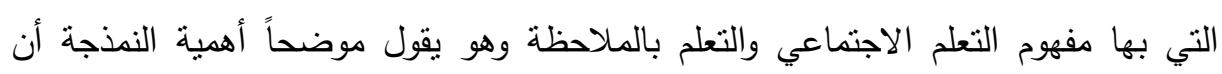

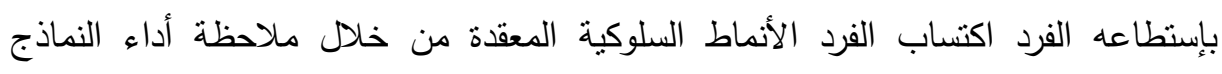

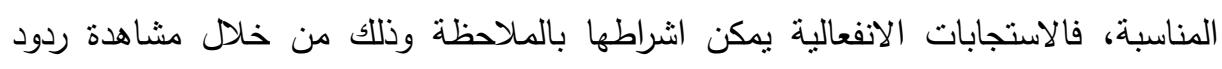

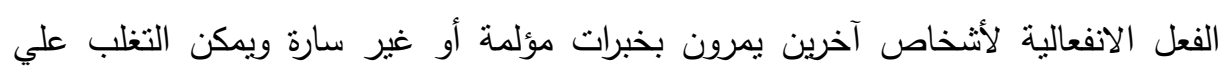
الخوف دون التعرض لعواقب سلبية ويمكن خفض السلوك من خلال مشاهدة آخرين يعاقبون عليه تأديته وأخيراً يمكن المحافظة علي إستمرارية أداء الفرد للإستجابات المتعلمة وتنظيمها

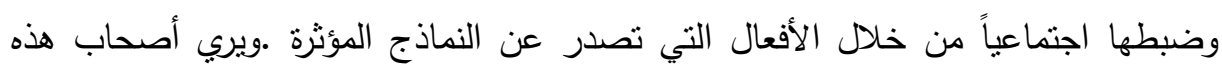

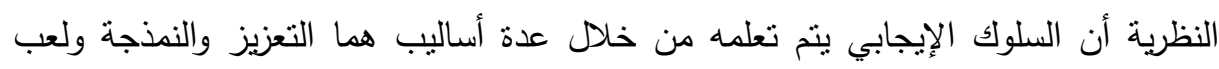
الدور والاستماع الي القصص وتري الباحثة ان هذه النظرية قد لعبت دوراً كبيراً في تفسيرها

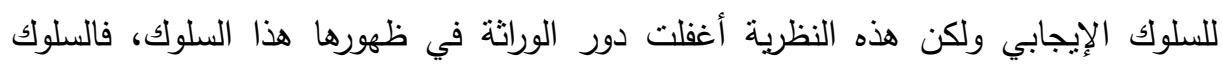
الإيجابي كأب سلوك يمكن ان يبدأ كأستعداد موروث لدي الفئي الفرد.

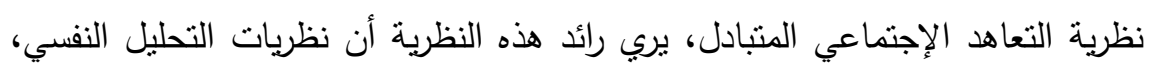

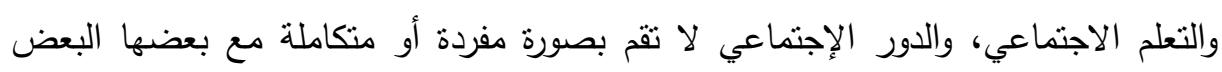

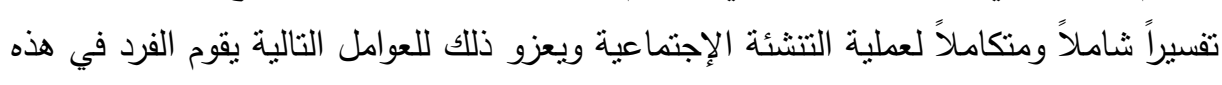

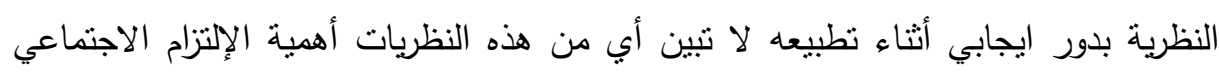

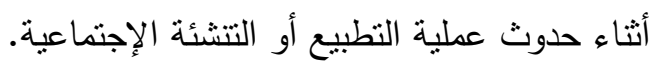

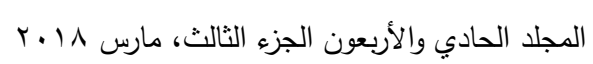




\section{إجراءايه الصراسلا}

عينة البحث: تتألف عينة الدراسة من (•r) أمهات أطفال ذاتوايين من الملتحقين بجمعية

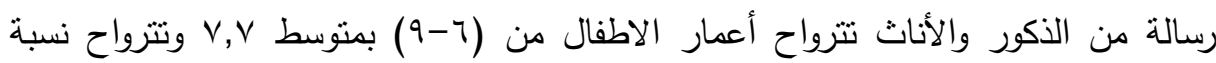

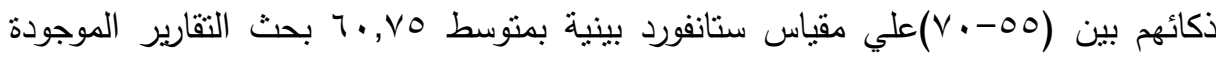
بسجلاتهم. هذا وقد نم تقسيم أفراد العينة الي مجموعنين منساويتين في العدد تتألف كل منهما

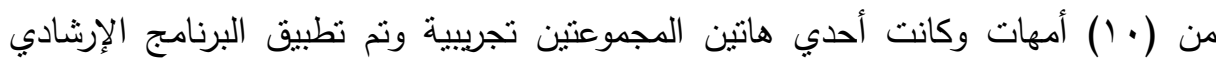
المستخدم ومجموعة ضابطة لم تخضع لأي إجراء تدريبي أو تجريبي ولم تحضر الأمهات جلسات التدريب. خصائص العينة: ترواحت أعمار الامهات من (س (ب-Y؟). الوالدان غير منفصلين. المستوي التعليمي جيد. وجود طفل ذاتوي واجد فقط في الأسرة. أدوات الدراسة: إعتمدت هذه الدراسة علي مقياس الرعاية الوالدية (اعداد الباحثة). خطوات اعداد المقياس: ا. اعد المقياس بهدف توفير أداة سيكومترية مستمدة من البيئة العربية لتتاسب اهداف الدراسة وعينتها. r. الإطلاع والإستعانة ببعض المقاييس التي اهتمت بموضوع الرعاية الولدية منل مقياس الرعاية الأبوية للطفل (99 ( ) ).

r. تم عمل دراسة استطلاعية علي عينة قوامها (rه) مفردة بهدف التعرف علي أبعاد الرعاية

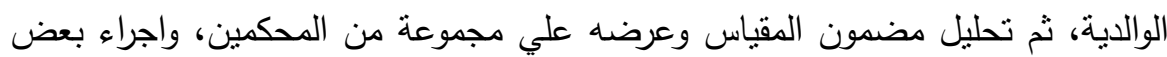
التعديلات، ثم التحقق من صدق مقياس الرعاية الوالدية.

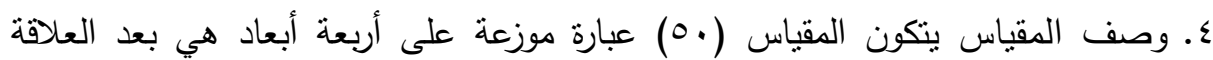

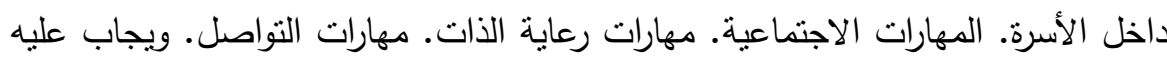
(نعم)، (لا)، (الي حد ما) وقد تم صياغة هذه العبارات في ضوء الدحكات التهات التي حددها

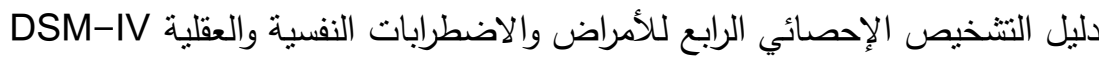

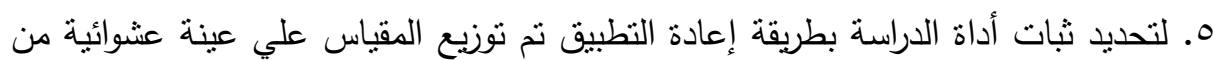

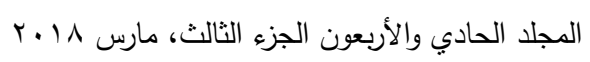


آباء وأمهات اطفال ذاتوبين من غير عينة الدراسة الاصلية وبطريقة إعادة التطبيق بفارق زمني (ع () يوما بين النطبيق الأول والتطبيق الثاني وتم حساب معامل ارتباط بيرسون

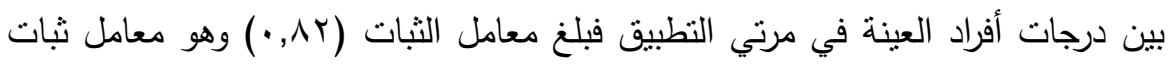
كما تثير الأدبيات والدراسات.

الثبات والصدق للمقياس: إذا زادت قيمة ألفا للمقياس عن (0, •) أمكن الإعتماد على عبارات المقياس وتطبيقه على عينة الدراسة. جدول(1) : نبات عبارات أبعاد المقياس

\begin{tabular}{|c|c|c|}
\hline قيمة ألفا & عدد العبارات & أبعاد المقياس \\
\hline$\cdot, 991$ & $1 \varepsilon$ & العلاقات داخل الأسرة \\
\hline$\cdot, 9 \leqslant 0$ & 11 & رعاية الذات \\
\hline., 97. & $1 \leqslant$ & المهارات الاجتماعية \\
\hline$\cdot, 999$ & $\Lambda$ & مهارات التواصل \\
\hline$\cdot, 990$ & $\varepsilon V$ & إجمالى المقياس \\
\hline
\end{tabular}

يتضح من الجدول السابق أن قيم معاملات الثبات مرتفعة حيث بلغت قيم معامل الثبات

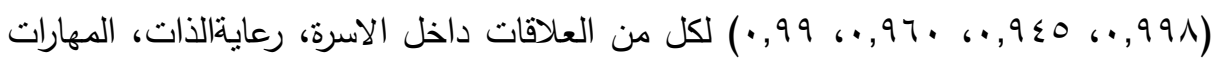
الاجتماعية، مهارات التواصل، وكانت قيمة ألفا لإجمالي المقياس (990,·•) وهي قيمة مرتفعة، ونتثير تلك القيم من معاملات الثبات إلى صلاحية عبارات المقياس وإمكانية الاعنماد

$$
\text { على نتائجه والوثوق بهاه }
$$

صدق الإتساق الداخلي للمقياس: تم حساب معاملات ارتباط كل بعد من أبعاد المقياس بالدرجة الكلية وقامت الباحثة بحساب صدق الإتساق الداخلي ومعامل الارتباط الدصحح كالآتي.

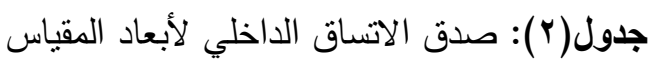

\begin{tabular}{|c|c|c|}
\hline الإجمالي & \multicolumn{2}{|c|}{ أبعاد المقياس } \\
\hline$(* *) \cdot, 999$ & معامل ارتباط بيرسون & \multirow{2}{*}{ العلاقات داخل لأسرة } \\
\hline,,$\ldots 1$ & الدلالة المعنوية & \\
\hline$(* *) \cdot, 99 \wedge$ & معامل ارتباط بيرسون & \multirow{2}{*}{ رعاية الذات } \\
\hline$\cdot, \cdot, 1$ & الدلالة المعنوية & \\
\hline$(* *) \cdot, 99 \mathrm{~V}$ & معامل ارتباط بيرسون & \multirow{2}{*}{ المهارات الاجتماعية } \\
\hline$\cdot, \ldots 1$ & الدلالة المعنوية & \\
\hline$(* *) \cdot, 999$ & معامل ارتباط بيرسون & \multirow{2}{*}{ مهاراتالتواصل } \\
\hline$\cdot, \ldots 1$ & الدلالة المعنوية & \\
\hline
\end{tabular}

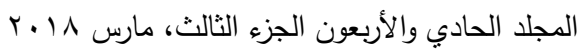


من جدول صدق الاتساق الداخلي السابق لأبعاد المقياس نجد أن معامل الارتباط بين

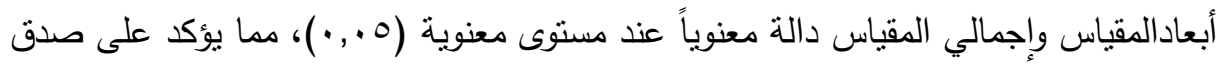

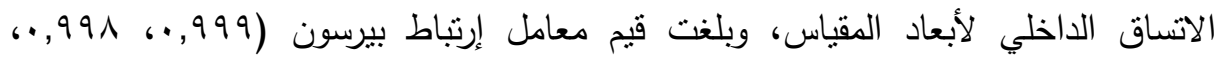

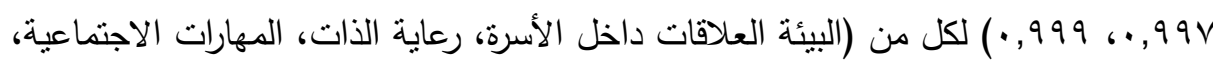
مهارات التواصل) على التوالي، وهي قيم تؤكد على صدق أبعاد المقياس. المعالجة الاحصائية: أسلوب مان وتتي، معامل ارتباط بيرسون، المنوسطات والانحرافات المعيارية.

\section{نمائيج التراسلا}

جدول(r)

\begin{tabular}{|c|c|c|c|c|c|c|c|c|c|}
\hline \multirow{2}{*}{$\begin{array}{l}\text { Lे } \\
\underline{E}\end{array}$} & \multirow{2}{*}{ Z } & \multirow{2}{*}{ U } & \multicolumn{3}{|c|}{ 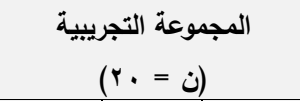 } & \multicolumn{3}{|c|}{ 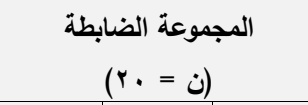 } & \multirow{2}{*}{ أبرعادة مقياس الوالدية } \\
\hline & & & E. & $E_{i}^{E}$ & r & $\stackrel{E}{E}$ & $\underline{E} \underline{E}$ & r & \\
\hline غير دال & . & $1 ., 0$. & $r \cdot, \Lambda$ & $0, r$. & $r \varepsilon, V$ & דr, & 0,9 . & $r$ & العلاقات داخل الاسرة \\
\hline غير دال &., 419 & $11, \ldots$ & $r r, \wedge$ & $0, v$. & $r 0, r$ & $r_{1,7}$ & $0, \varepsilon$. & $r \leqslant, 0$ & المهارات الاجتماعية \\
\hline غير دال &., 1.0 & Ir,.. & rr & 0,0 & rY,T & rr & 0,0 & $r r, 1$ & رعاية الذات \\
\hline غير دال & صفر & Ir,o. & $r 1, r$ & $0, \varepsilon$. & $0, \varepsilon$ & rr, & 0,7 & $Y, Y$ & مهارات التواصل \\
\hline غير دال &., 1.0 & $1 r, \ldots$ & r r, $\varepsilon$ & $\bullet, 7$ & $\wedge \vee, q$ & r $1, r$ & $\bullet, r$. & $\wedge q, 1$ & مجموع الابعاد \\
\hline
\end{tabular}

أظهرت النتائج عدم وجود فروق ذات دلالة إحصائية بين الامهات في المجموعتين

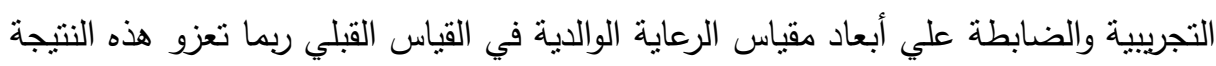

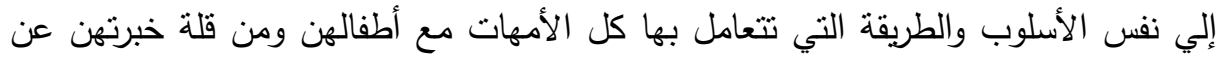

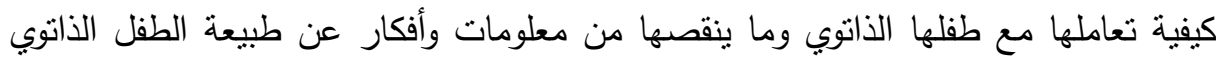

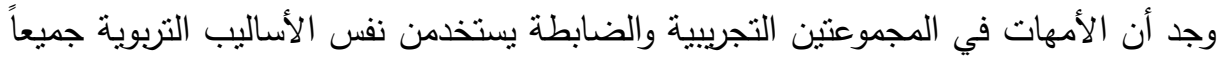
وفي بعض الاحيان يعاملن طفلهن كما يعاملن الطفل العادي إن نقص المعلومات والخبرات

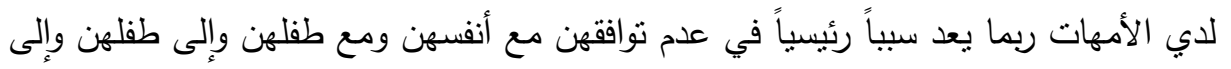

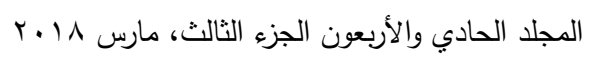


أسلوب رعاية مناسبة لطفلها ،حيث أظهرت الأمهات درجات متفاوتة من الرعاية الوالدية بين السلبية والايجابية ،وبين الحب والعطف الزائد وبين القلق علي مستقبل الطفل من حيث عدم مقدرته علي المشاركة الاجتماعية والتفاعل الاجتماعي المناسب مع أقرانه وبيئته المحيطة بها مانها

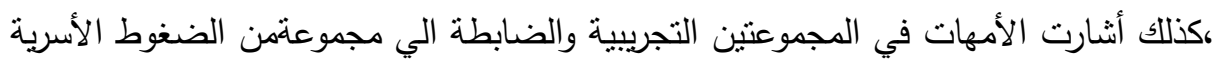
والاجتماعية والاقتصادية التي يتعرضن لها وكذلك أثنارت الأمهات الي عدد من المشاكل

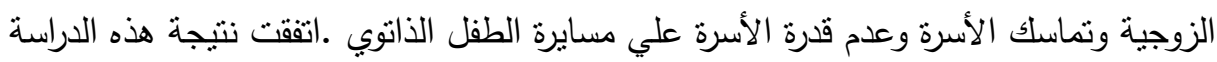

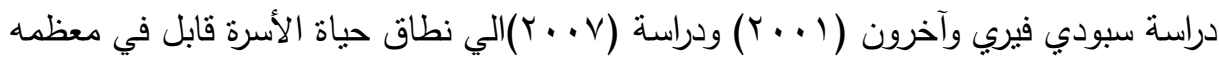

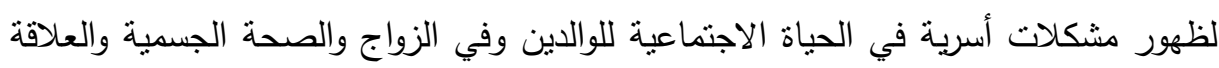

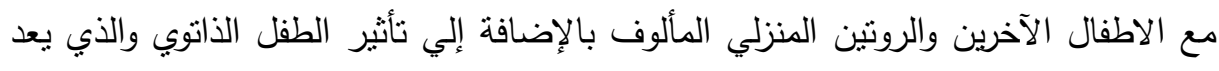
سلبياً تماماً. في ضوء ما توصلت اليه نتائج الدراسة استطاع الباحث أن يستتنج الآتي:-

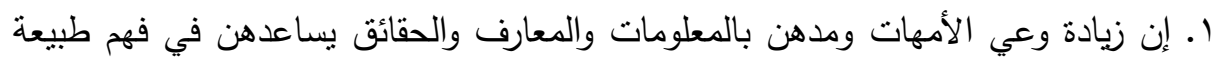
إعاقة الذاتوية.

r. إن تدريب الامهات علي أساليب ومهارات حياتية يساعدهن علي تقديم رعاية والدية قائمة علي تقبل الطفل وتفهم لحاجاته وسلوكياته المضطربة. r. إن إثراك الوالدين في برامج التدريب الخاصة بالطفل الذاتوي يزيد من مساعدة الأسرة في وسئه

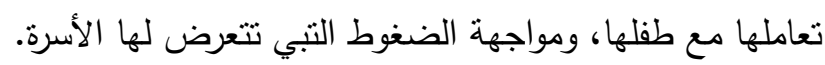
ع. إن إقامة علاقة وطيدة بين الأب والأم والطفل الذاتوي يساعد في التخفيض من أعرض أعراض الاض الذاتوية لديه.

$$
\text { في ضوء نتائج الدراسة يوصي الباحثون بالآتي: }
$$

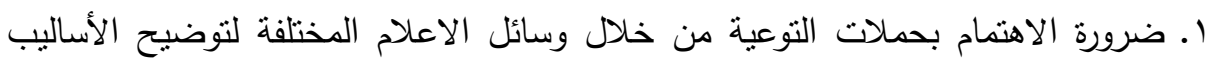
والطرق المناسبة التي يمكن للوالدين التعامل مع أطفالهن الذاتوبين. r. ضروة تفعيل دور الأم في تعليم وتدريب الطفل الذاتوي من خلال إقامة الدورات وورش لهن

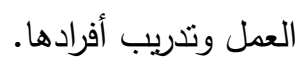

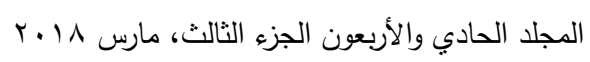


مجلة العلوم البيئية

معهد الدراسات والبحوث البيئية - جامعة عين شمس له

r. ضرورة نوفير فريق عمل متكامل ينولي هذه الفئة من طبيب أطفال، طبيب نفسي،

$$
\text { أخصائي نفسي إلي جانب المدرسة والأسرة . }
$$

ع. . ضرورة الاهتمام بتقديم المزيد من البرامج الارشادية لامهات الاطفال الذاتوايين في سبيل

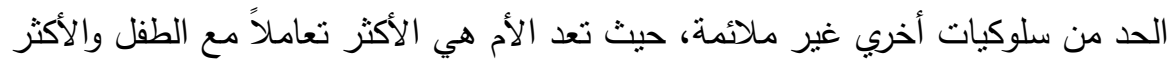
احتكاكاً به والأكثر تلبية لاحتباجاته.

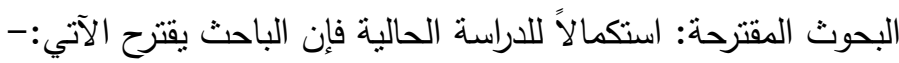
ا ـ دراسة لبعض المشكلات الأسرية للأسر التي بها طفل ذاتوي. r. فعالية برنامج تدريبي للحد من الاضطرابات السلوكية لاي الطفل الذاتوي.

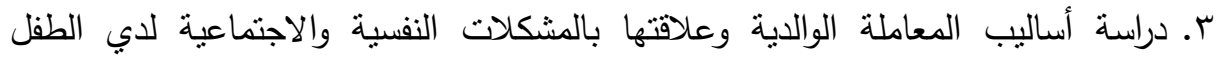
الذاتوي، دراسة لأهم الضغوط النفسية وأثز الطفل الذاتوي علي الأسرة.

\section{enlall}

إلهامي عبد العزيز (999 (19): سيكولوجية الفئات الخاصة دراسة في حالة الذاتوية طا، القاهرة،

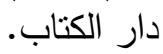

إسماعيل شرف: مدي فاعلية العلاج بالحياة اليومية في تحسن حالات الأطفال ذوي التوحد

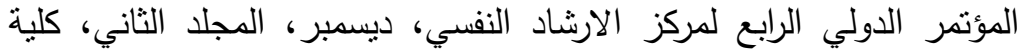

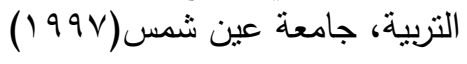

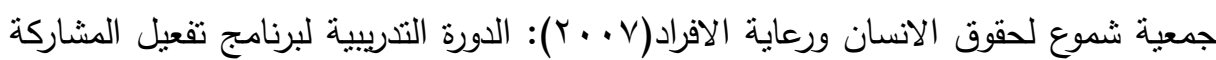

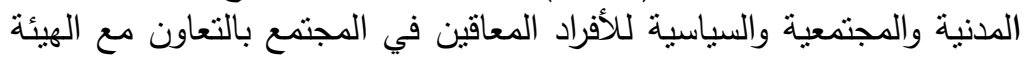
USID الأمريكية للتنمية الدولية والمبية

فاتن توفيق، محمد صالح(99V (1): ردود الأفعال النفسية لدي الطفل المعوق عقليا، مجلة

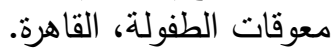

لويس كامل مليكة(1991): الاعاقات العقلية والاضطرابات الارتقائية طا، القاهرة، مكتبة النهضة العربية.

اكرام عبد الحميد(؟ ( ب): فعالية برنامج ارشادي للآباء قائم علي استخدام لغة الجسد لتتمية

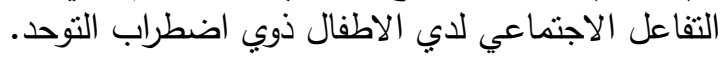

$$
\text { المجلد الحادي والأربعون الجزء الثالث، مارس ^| • ب }
$$


جمال أحمد شفيق وآخرون

ماجد السيد عمارة(0 . ب): إعاقة التوحد بين التشخيص والتتخيص الفارق طا، القاهرة كمكتة النهضة العربية.

نادية ابراهيم(10 ب): الطفل التوحدي في الاسرة، سلسلة ذوي الاحتباجات الخاصة، الاسكندرية ، مؤسسة حورس الدولية.

\title{
THE EFFECTIVNESS OF A PROGRAM FOR DEVELOPING POSITIVE BEHAVIOR OF MOTHERS TOWARDS THEIR CHILDREN WITH SPECIAL NEEDS
}

\author{
Shafiq, J. A. ${ }^{(1)}$; El-Dahan, Mona, H. ${ }^{(2)}$; Hani, A. F. ${ }^{(3)}$ \\ and Hassan, Rehab, Sh.
}

1) Higher Institute of Motherhood \& Childhood, Ain Shams University 2) Faculty of Specific Education, Ain Shams University 3) Institute of Environmental Studies \& Research, Ain shams University

\begin{abstract}
The aim of this study is to develop the positive behavior of mothers in order to help their children to agree, communicate and adapt to those around them, as well as raise the efficiency of the mother-child relationship in order to achieve a psychological atmosphere suitable for the child's development. The sample of the study consisted of (20) mothers of autistic children who enrolled in a male and female letter association with children aged 6-9 years.

The study was based on a combination of descriptive and experimental approaches. A range of statistical methods such as Mann Whitney, Pearson correlation coefficient, mean and standard deviations were used.
\end{abstract}

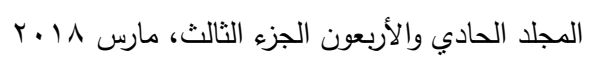




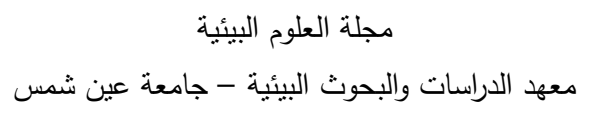

The study reached a number of results, including training mothers in life styles and skills that helps them to provide parental care based on the child's acceptance and understanding of their needs and troubled behavior, establishing a close relationship between father and mother and child self help to reduce the symptoms of autism. It also concluded a number of recommendations, including the need to pay attention to providing more guidance programs for mothers of self-children in order to reduce other behaviors inappropriate, as the mother is the most dealing with the child and the most contact and more to meet the needs. 